\title{
ESTUDO DO DEFEITO MARCA MECÂNICA LAMINADA EM AÇOS AISI 430 LAMINADOS A FRIO*
}

\author{
Angelo Ferreira Costa ${ }^{1}$ \\ Ronaldo Antônio Neves Marques Barbosa ${ }^{2}$ \\ Jose Carlos Batista ${ }^{3}$ \\ Antonio Carlos Ataide 4
}

Resumo

O laminador a frio de inoxidáveis LB1 da Aperam South America é um laminador Sendzimir reversível que produz materiais alta exigência de qualidade superficial destinados a aplicações nobres como baixelas, mesas de fogão e portas de geladeira de alto luxo. 0 rendimento físico destes materiais passou a ser comprometido com a identificação de um defeito caracterizado por pequenas marcas, sem presença de óxidos ou inclusões que ocorrem ao longo da bobina, nas duas faces e na borda do lado de acionamento do laminador. Nos anos de 2009 a 2010 o defeito ocorria em 45\% da produção de materiais finos de aços 430 processados no LB1. O defeito passou a ser codificado como S163 Marca Mecânica Laminada. Para abordagem ao problema foi reunida equipe multifuncional com representantes das áreas de Operação, Manutenção, Metalurgia, Inspeção, dentre outras, utilizando a metodologia de Domínio Integrado do Processo (DIP). Após a análise das causas e a implantação dos planos de ação do projeto, houve o decréscimo acelerado da ocorrência do defeito. A causa fundamental do defeito foi caracterizada como o desalinhamento da desbobinadeira, provocando um efeito de empeno lateral no material durante a laminação do primeiro passe. Em Agosto de 2012 houve a primeira intervenção de correção na desbobinadeira do LB1, reduzindo os índices de ocorrência do defeito para $11 \%$ no mês de Setembro de 2012 e posteriormente reduzindo para percentuais inferiores a $1 \%$ a partir de Janeiro de 2013, superando as metas propostas para o projeto.

Palavras-chave: Laminação a frio; Laminador Sendzimir; Marca mecânica; AISI 430.

\section{STUDY OF ROLLED MECHANICAL MARK DEFECT IN AISI 430 COLD ROLLED STEEL}

\section{Abstract}

The defect rolled mechanical mark (S163) is characterized by small marks without the presence of oxides or inclusions that occur along both sides of the coil and the edge of the drive side of the Sendzimir mill 1 - LB1 at Aperam South America. From 2009 to 2010 it occurred in about $45 \%$ of production ( $585 \mathrm{t} /$ month) of thin materials of P430A steel processed in LB1, to which high-grade surface quality is required, just the preferred route of these products. To approach the problem in 2011 was pooled cross-functional team comprised of representatives from the operation, maintenance, metallurgy, inspection, among others, using the methodology IPM - Integrated Process Mastery. Through IPM methodology steps of the defect characterization, identification of potential causes through the FMEA tool, prioritizing major cause, action plan, monitoring and analysis of results were developed. As a result, a reduction in the rates of occurrence of the defect in 2012 to $28 \%$ in 2013 to $1.0 \%$ was obtained. After this result we could return to production of steels P430A for all applications in material produced in LB1 due process stability.

Keywords: Cold rolling; Sendzimir mill; Mechanical brands; AISI 430.

1 Engenharia Mecânica, Mestrando, Metalurgista de Processo, Gerência de Laminação a Frio de Aços Inoxidáveis, Aperam South America, Timóteo, Minas Gerais, Brasil.

2 Engenharia Mecânica, D.Sc., Professor do Departamento de Engenharia Metalurgica e de Materiais, UFMG, Belo Horizonte, Minas Gerais, Brasil.

3 Engenharia Mecânica, M.Sc., PMP, Metalurgista de Processo, Gerencia de Metalurgia dos Aços Inoxidáveis, Aperam South America, Timóteo, Minas Gerais, Brasil.

4 Engenharia Mecânica, M.Sc., Engenheiro de Manutenção, Gerência de Laminação a Frio de Aços Inoxidáveis, Aperam South America, Timóteo, Minas Gerais, Brasil.

5 Administração, Técnico de controle de processos, Gerência de Laminação a Frio de Aços Inoxidáveis, Aperam South America, Timóteo, Minas Gerais, Brasil.

\footnotetext{
* Contribuição técnica ao $51^{\circ}$ Seminário de Laminação - Processos e Produtos Laminados e Revestidos, 28 a 31 de outubro de 2014, Foz do Iguaçu, PR, Brasil.
} 


\section{LAMINAÇÃO \\ Rolling}

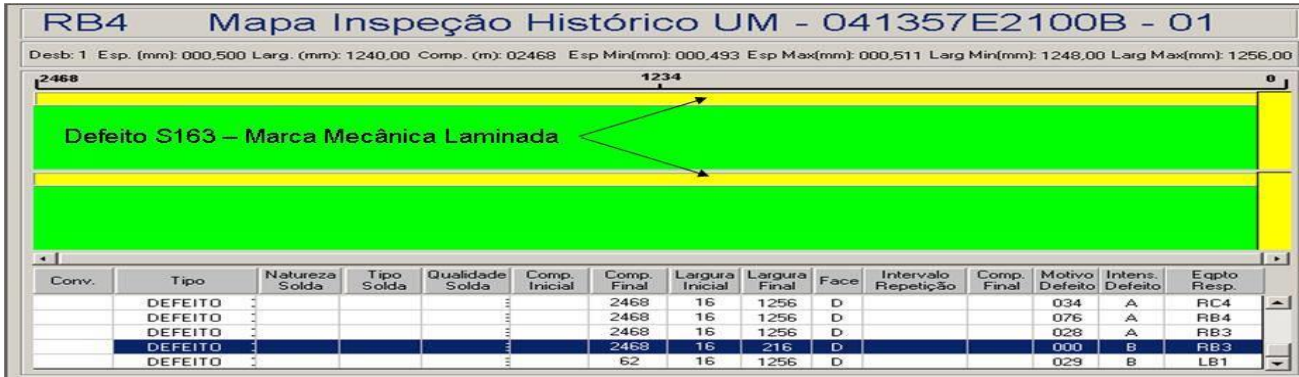

Figura 1 - Posicionamento do defeito $S 163$

Ao analisar o defeito no microscópio ótico e também no microscópio ótico de varredura (MEV) pôde detectar que o defeito caracteriza-se por pequenas marcas sem presença de óxidos ou inclusões, conforme mostrado na figura 2.
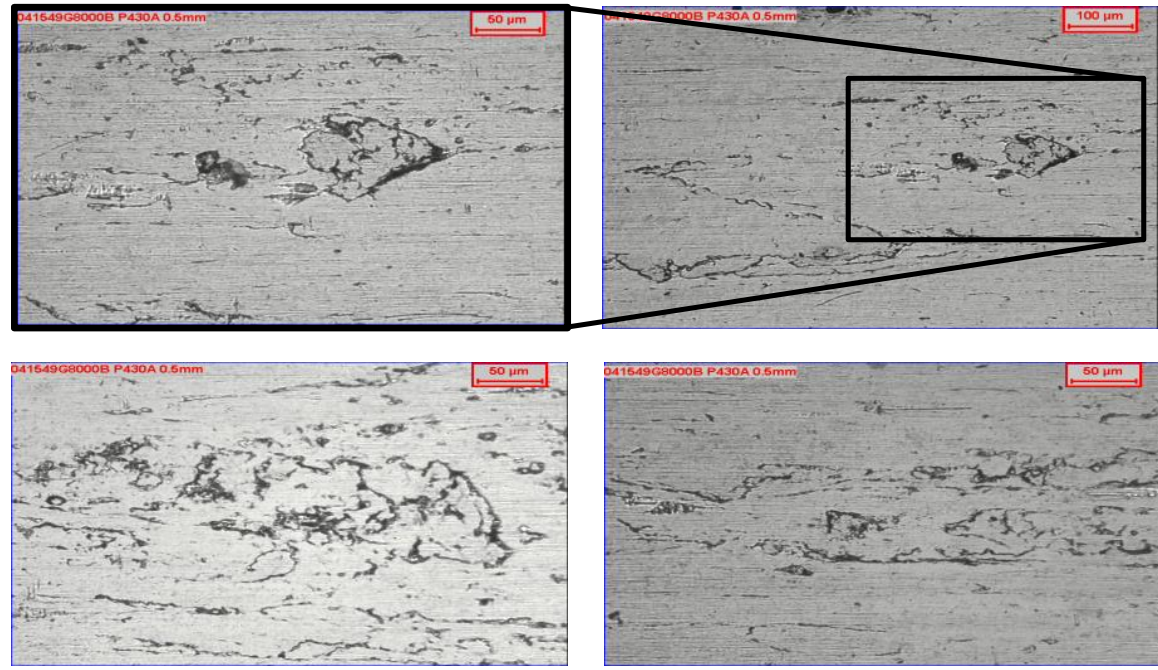

Figura 2 - Análise defeito S163

As medições de micro dureza na amostra com o defeito S163, nas posições próximas ao defeito, em cima do defeito e no meio da amostra com o defeito apresentam variações normais, não indicando aumento de dureza em função da presença do defeito.

Tabela 1. Medição de Micro dureza na amostra de S163

\begin{tabular}{cccc}
\hline Medição & $\begin{array}{c}\text { Próximo ao } \\
\text { defeito (HV10) }\end{array}$ & $\begin{array}{c}\text { No defeito } \\
\text { (HV10) }\end{array}$ & $\begin{array}{c}\text { No centro da tira } \\
\text { (HV10) }\end{array}$ \\
\hline 1 & 276,71 & 338,17 & 302,55 \\
\hline 2 & 282,02 & 307,75 & 287,61 \\
\hline 3 & 289,08 & 306,87 & 302,43 \\
\hline
\end{tabular}

\subsection{Levantamento dos Parâmetros Críticos do Processo (PCPs)}

Como inicio das atividades juntamente com a equipe de operação, manutenção, controle de processo e Metalurgia foi realizado "Brainstorming" com todas as equipes e levantado os 105 parâmetros Crítico de processo (PCPs), sendo classificados em 10 sub-processos: Cadeira de laminação, Rolos enxugadores, $1^{\circ} \mathrm{e}$ $2^{2}$ cilindros intermediários, Processo, Óleo refrigerante, Pay-off, Sistema de refrigeração, Bobinadeiras, Rolamento e Rolos. 


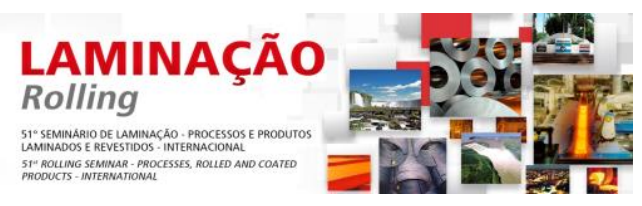

\subsection{Análise Estatística do Processo de Laminação do Aço P430 no LB1}

A análise estatística do processo foi realizado com a ajuda do Software Flash Process $\AA$, onde foram correlacionados os principais parâmetros de processo, como: Trações utilizadas nos passes de laminação (Tração à frente e a Ré), pressão de óleo de refrigeração, pressão dos rolos enxugadores, redução por passe, velocidade de laminação, força de laminação e diferença de tração entre tração à frente e a Ré. A análise mostrou correlações de baixo índice para todos os parâmetros de processo, como pode ser visto na Figura 3.

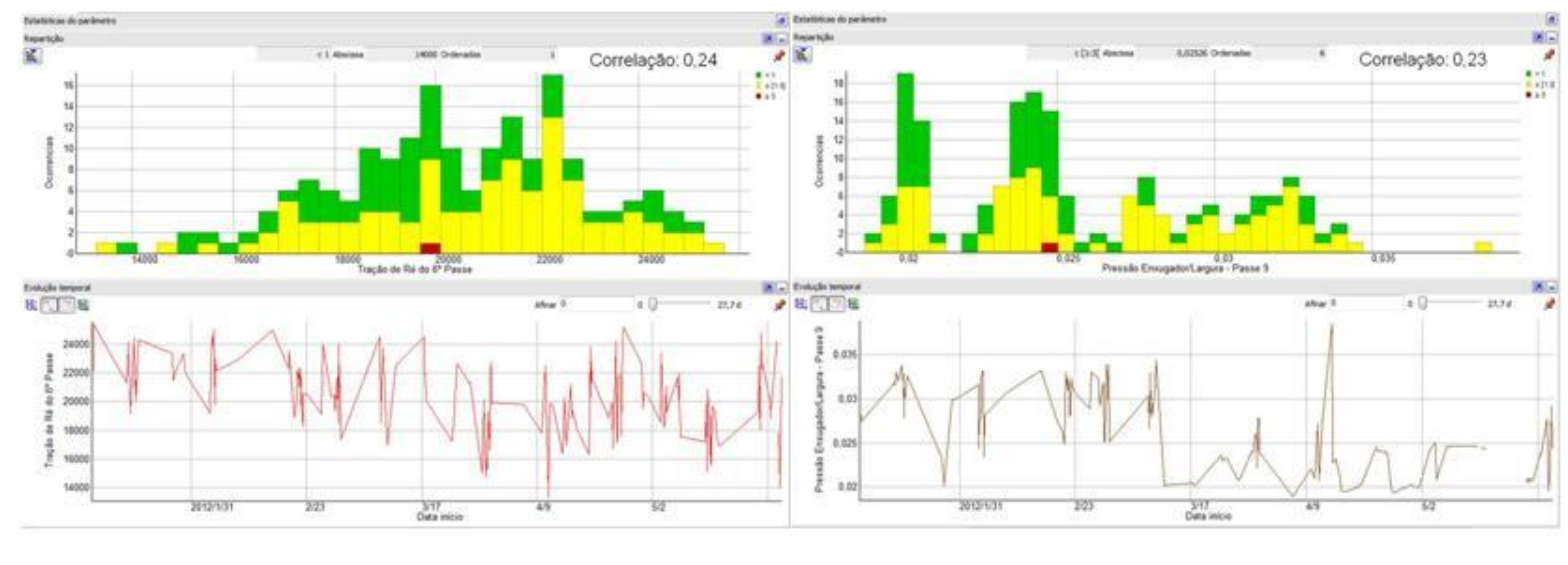

a)

b)

Figura 3 - a) Análise estatística da influencia do tração a ré do $6^{\circ}$ passe na ocorrência do defeito S163. b) Influência da pressão dos rolos enxugadores na ocorrência do defeito S163.

Em função dos resultados obtidos na analise dos dados estatísticos dos parâmetros de processo, iniciou os estudos da influência da desbobinadeira (Pay-off), mostrado na Figura 4, na ocorrência do defeito. Elaborado a experiência de processo (EXP171204) para realização de testes de processamento de bobinas P430A com laminação iniciada no laminador de bobinas $n^{\circ} 4$ (LB4) e término no LB1. Os testes iniciais foram:

- Condição 01 - Laminar os cinco primeiros passes de 3 bobinas de P430A no LB4 e termino da laminação das bobinas no LB1.

- Condição 02 - Laminar os três primeiros passes de 3 bobinas de P430A no LB4 e termino da laminação das bobinas no LB1.

- Condição 03 - Laminar o primeiro passe de 3 bobinas de P430A no LB4 e termino da laminação das bobinas no LB1.

Foram laminadas 03 bobinas nas condições 01 e 02 e as mesmas não apresentaram o defeito marca mecânica laminada. O teste na condição 03 também repetiu os resultados, não apresentando o defeito, mostrando assim uma forte indicação de falha no processo do primeiro passe de laminação do aço P430A no Laminador Sendzimir 1.

\subsection{Análise da desbobinadeira (Pay-off) do LB1}

Em função da possibilidade de falha na desbobinadeira do laminador Sendzimir 01 foram elaborados estudos de manutenção mecânica e eletroeletrônica nos componentes da desbobinadeira, mostrada na Figura 4.

\footnotetext{
* Contribuição técnica ao $51^{\circ}$ Seminário de Laminação - Processos e Produtos Laminados e
} Revestidos, 28 a 31 de outubro de 2014, Foz do Iguaçu, PR, Brasil. 


\subsubsection{Tração da desbobinadeira do LB1}

O Cálculo das trações da Pay-off do LB1 foi realizado pela equipe de Engenharia, comparando os valores de tração definidos pelo projeto original do equipamento $\mathrm{e}$ cálculos dos valores reais. Foram realizadas medições das variáveis do acionamento que determinam a força de tracionamento da pay-off do LB1: Tensão e corrente de armadura, velocidade angular da armadura e velocidade linear, durante as medições. Os cálculos mostraram um valor de tração da pay-off de 5,5 toneladas, que estão de acordo com o projetado para o equipamento.

Foram realizados registros destas variáveis utilizando o software de monitoramento do equipamento e não foi verificada nenhuma anormalidade relacionada com estas variáveis.

\subsubsection{Alinhamento da desbobinadeira}

A medição topográfica da desbobinadeira (Pay-off) do laminador mostrou um desalinhamento de $5 \mathrm{~mm}$ no eixo da pay-off em relação à cadeira de laminação, que estava fora das tolerâncias especificadas pelo projeto do equipamento.

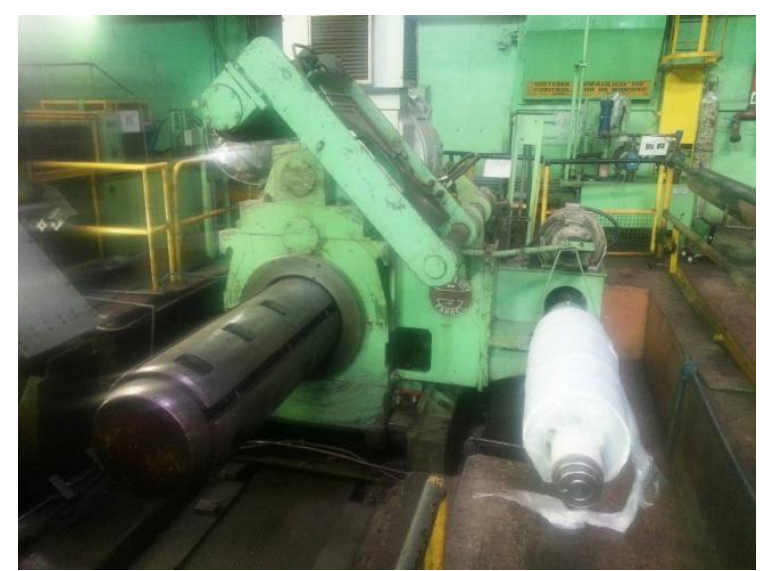

Figura 4. Desbobinadeira (Pay-off) do LB1

O conjunto da desbobinadeira possui deslocamento na direção do eixo do mandril, a fim de centralizar a tira na cadeira, durante o primeiro passe de laminação. $O$ projeto prevê uma base móvel montada sobre 4 rodas de deslocamento, para suportar o esforço vertical e 4 rolamentos laterais que suportam o esforço de tração na tira e garante $o$ alinhamento do conjunto.

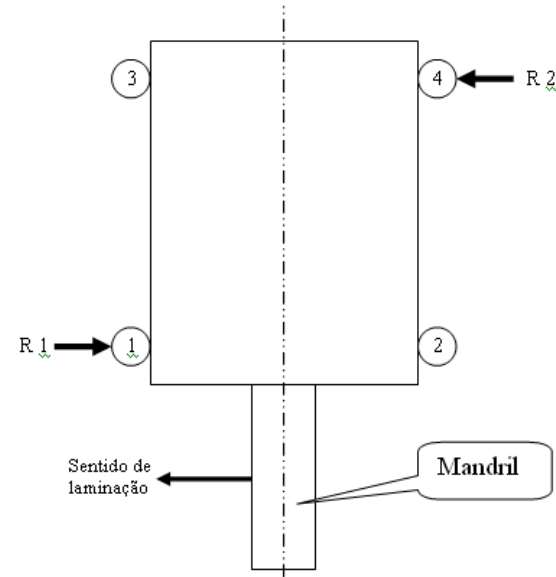

Figura 5 - Esboço das guias laterais da desbobinadeira do LB1

\footnotetext{
* Contribuição técnica ao $51^{\circ}$ Seminário de Laminação - Processos e Produtos Laminados e
} Revestidos, 28 a 31 de outubro de 2014, Foz do Iguaçu, PR, Brasil. 


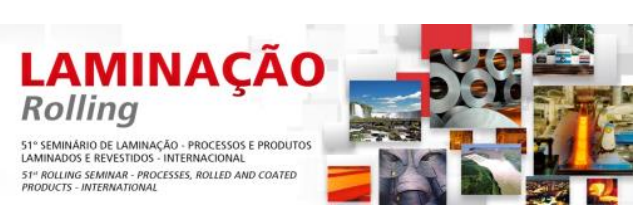

A Figura 5 apresenta um esboço das guias laterais da desbobinadeira e os quatro rolamentos de guia. Uma avaliação do esforço de tração, bem como das reações de apoio, permite afirmar que o rolamento 1 é o mais solicitado do conjunto. $E$ através de observação no local, verificou-se que a causa do desalinhamento estava diretamente relacionado com este rolamento.

Os rolamentos utilizados são do tipo "rolos de leva com eixo" Eles são caracterizados por um anel externo de parede espessa, que lhes permite acomodar elevadas cargas radiais e de choque. A superfície de rolagem do anel externo é abaulada por padrão. Em vez de um anel interno, os rolos de leva com eixo possuem um pino sólido rosqueado, de maneira que o rolo de leva com eixo possa ser fixado rápida e facilmente aos componentes apropriados através de uma porca sextavada. Analise realizada pela equipe de Engenharia de Manutenção detectou que o rolamento número 1 apresentava não conformidade com o projeto original do equipamento. Após desmontagem do conjunto foi confirmado o empeno do eixo. A Figura 6 mostra o detalhe do projeto original da guia lateral.

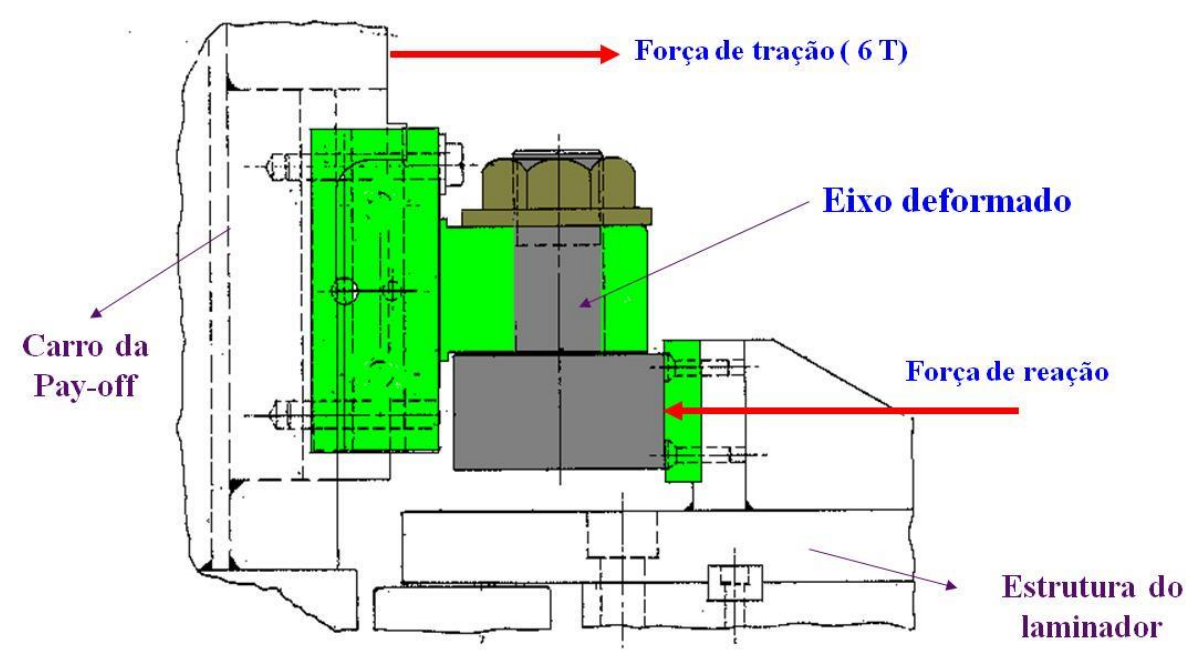

Figura 6 - Análise da deformação do eixo do rolamento da desbobinadeira

\subsection{Análise de Falha da Desbobinadeira}

A análise de falha referente ao rolo de guia da desbobinadeira mostrou que a resistência mecânica do eixo da roda guia estava abaixo dos esforços gerados pela tração na tira. A causa fundamental da falha foi à montagem de uma roda guia não adequada para a função proposta. As ações para a correção da falha foram implantadas foram: substituição do conjunto atual composto de eixo, buchas e roda por um rolamento de leva conforme projeto original; verificação com recurso topográfico semestralmente, confecção de controle visual na base móvel para verificação do posicionamento, medição topográfica na bobinadeira da saída dos equipamentos anteriores foram determinantes para a eliminação do defeito marcas mecânicas laminadas.

\subsection{Resultados Obtidos}

Após a implantação dos planos de ação previstos para a correção da falha, houve o decréscimo acelerado da ocorrência do defeito S163, conforme mostrado na Figura 7. Em Setembro de 2012 houve a primeira intervenção na desbobinadeira do * Contribuição técnica ao $51^{\circ}$ Seminário de Laminação - Processos e Produtos Laminados e
Revestidos, 28 a 31 de outubro de 2014, Foz do Iguaçu, PR, Brasil. 


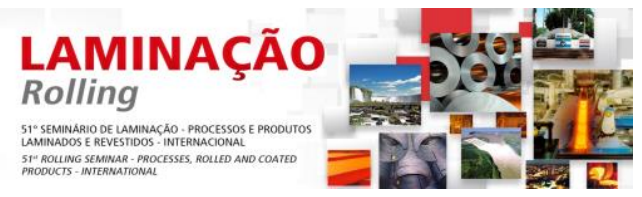

LB1, reduzindo os índices de CCF do defeito de um percentual de aproximadamente $32,1 \%$ (585 t/mês) para 11\% (143 t/mês) no mês de Setembro de 2012.

A ocorrência do defeito, conforme mostra a Figura 7, apresentou queda nos meses seguintes, estabilizando em um percentual inferior a $1 \%$ (10 t/mês), considerado normal para as ocorrências dos defeitos.

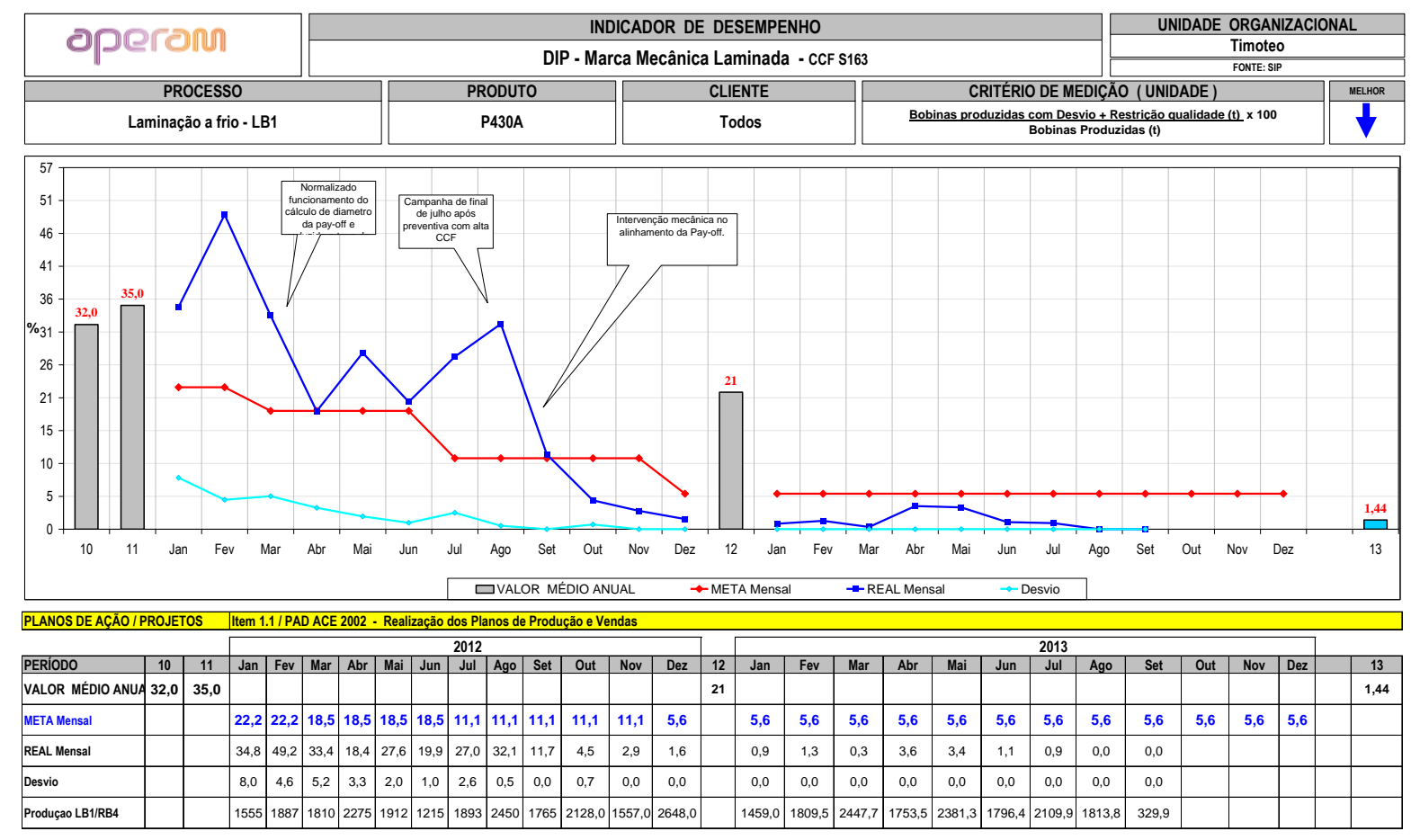

Figura 7 - Indicador de desempenho do S163 após a Implantação do DIP.

\section{CONCLUSÃO}

O defeito Marca Mecânica Laminada apresentava-se de forma moderada, concentrada apenas no material P430A processado no LB1. As marcas inicialmente caracterizadas como sendo geradas no processo de recozimento inicial foram estudadas de forma profunda, com o apoio da metodologia de domínio integrado do processo (DIP), que possibilitou o estudo de uma forma ampla, por uma equipe multifuncional.

A causa fundamental do defeito foi caracterizada como o desalinhamento da desbobinadeira, provocando um efeito de empeno lateral no material durante a laminação do primeiro passe. $O$ entendimento do efeito da torção dentro da cadeira não foi abordado no trabalho em função das complexas atuações de forças durante a laminação dos aços em laminadores do tipo Sendzimir.

As ações de manutenção para a eliminação da falha foram lançadas no sistema de manutenção Máximo, com o objetivo de evitar recorrências.

A equipe do DIP S163 recomenda que todas as intervenções de modificações de equipamentos sejam amplamente estudas antes da implantação, uma vez que podem de alguma forma interferir no funcionamento do equipamento e afetar a qualidade do produto. 


\section{BIBLIOGRAFIA}

1 Lovato Neto C. Simulação numérica da laminação a frio no laminador Sendzimir número 2 da Acesita. 86p. Dissertação de Mestrado - UFMG, Belo Horizonte, 2006.

2 Ginzburg VB. Steel - rolling technology: theory and practice. New York, Marcel Dekker Inc., 1989. p. 571-588.

3 Springorum D. Technologies of profile and flatness control for hot and cold rolled strip in Germany. In: Technology and performance of profile control for hot and cold rolled flat products - Technical Exchange Session. International Iron and Steel Institute, 1991, p. 27-32

4 Helman H, Cetlin PR. Fundamentos de Conformação Mecânica dos Metais. 2ed. Belo Horizonte: FCO, 1993. 170p.

* Contribuição técnica ao $51^{\circ}$ Seminário de Laminação - Processos e Produtos Laminados e Revestidos, 28 a 31 de outubro de 2014, Foz do Iguaçu, PR, Brasil. 